\title{
地中電線路の大地帰路相互インピーダンス の一検討
}

\author{
正員松 浦 虔士 (大阪大)
}

\section{1. まえがき}

多線条系の地中電線路の伝送特性を解析する場合， 対象之する周波数や大地の導電率に応じて，合理的な 大地㷌路相互インピーダンスを用いる必要がある。従 来, 架空電線路の大地帰路インピーダンスについて は, Carson 氏(1)や Pollaczek 氏 氏 $^{(2)}$ 計算式㧍よび, そ机らの計算式上りも高い周波数領域まで使える菊地

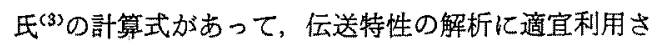
れている。

一方，地中電線路汇関しては，Pollaczek 氏が RGE 誌汇発表した論文(4)があるが，彼の導出した大地㷌路 相互インピーダンスの式は，無限級数の形で表現され ている。乙れは, 1926 年当時, 現在のような電子計算 機がなく，無限積分形の表現よりも手計算の容易な級 数形のほうが実用的であったためと思われる。

一方, Wedepohl 氏之Wilcox 氏は, 1973 年 Proc. IEE 誌に, 変位電流までは考慮しないが、比較的高周 波まで使える大地帰路相互インピーダンスの計算式を 新しく導出し発表した ${ }^{(5)}$ 。乙の導出では，電界に関す る偏微分方程式の解を, 地表面での境界条件を満たす ように，積分変換によって求めている。しかし，その 導出過程におりる数式や, 結果として示している大地 㷌路相互インピーダンスの計算式の中には多くの印刷 ミスが含まれており，不明りょうなあのとなってい る。彼らの求めた計算式㹥, 本来 $10 \mathrm{MHz}$ 程度まで の周波数領域で使用可能なはずである。事実, Wilcox 氏らは別の諭文 ${ }^{(6)}$ で $1 \mathrm{MHz}$ 以上の周波数領域を扱っ た解析例を示しているので，そてでは前記の諭文(5)で の印刷ミスを修正した計算式を使用しているすのと思 われるが、インピーダンスそのものの計算式は示され ていない。

An Investigation of Mutual Impedance of Underground Trans. mission Lines with Earth Return. By Kenji Matsuura, Member (Faculty of Engineering, Osaka University).

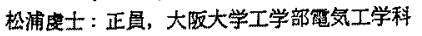

そこで本資料では，実用上必要とされる $10 \mathrm{MHz}$ 程 度までの大地帰路相互インピーダンス $Z_{m}$ の計算式を Pollaczek, Wedepohl 氏らとほぼ同様の仮定の下に 導出し直すと共に，使いやすい形に整理するととを試 みた。また，種々のケーブル布設間䧣に対する $Z_{m}$ の 数值計算図表を作成し，実用に資することにした。

\section{2. 基 本 式}

図1亿示すように，大気之接する境界面が無限平面 とみなせる大地の中に, 角周波数 $\omega(\mathrm{rad} / \mathrm{s})$ の電流 $\dot{I}$ (A) の流㣗る導体 $A$ が $x-y$ 平面に垂直方向に, 地表 から深さ $h(\mathrm{~m})$ のところに埋設されているとする。ま た導体 $A$ 之平行に導体 $B$ 少座標 $(X, Y)$ の位置に埋 設されており，以下，てれらの導体 $A, B$ 間の単位長 あたりの大地㷌路相互インピーダンス $\dot{Z}_{m}(\Omega / \mathrm{m})$ を次 の仮定のもとに計算する。

(i) 大地は均質一様上する。

（i） 遒体内の電流分布に与える大地の影響は無視 でき，導体外の場に対しては，導体の中心に線 状全電流 $\dot{I}$ が流れているものとして报える。

(面) 変位電流は無視する。

(iv) 導体は大地から絶縁されており, 無限に長い あのとする。

これらの仮定加ら，大気中の電界 $\dot{E}_{1}(x, y)(\mathrm{V} / \mathrm{m})$

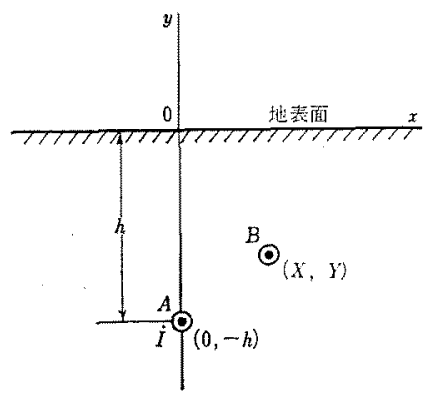

图 1 導体配列

Fig. 1. Conductor configuration. 
および地中の電界 $\dot{E}_{2}(x, y)$ に関して，次の式が成り 立つ (以下, 複素数を示す・は省略する)。

$$
\begin{array}{r}
\frac{\partial^{2} E_{1}}{\partial x^{2}}+\frac{\partial^{2} E_{1}}{\partial y^{2}}=0 \quad(y \geq 0) \ldots \ldots \ldots \ldots \ldots . . . . . .(1) \\
\frac{\partial^{2} E_{2}}{\partial x^{2}}+\frac{\partial^{2} E_{2}}{\partial y^{2}}=m_{e}{ }^{2} E_{2}+C_{0} \frac{m_{e}{ }^{2}}{\sigma_{e}} I \delta(x) \delta(y+h) \\
(y \leq 0) \ldots \ldots(2)
\end{array}
$$

乙とに, $m_{\mathrm{e}}=\sqrt{j \omega \mu_{\mathrm{e}} \sigma_{\mathrm{e}}}, \mu_{\mathrm{e}}$ : 大地透磁率 (H/

$\mathrm{m}), \sigma_{e}:$ 大地導電率 $(\mathrm{S} / \mathrm{m})$

また，Cは付録で導出したように，絶縁体の外半径 $r_{i}(\mathrm{~m})$ とすると, $C_{0}=\left\{m_{c} r_{i} K_{1}\left(m_{0} r_{i}\right)\right\}^{-1}$ で計算され る定数である。 $K_{1}(\cdot)$ は一次の第二種変形べッセル関 数である。ठは Dirack のデルタ関数である。

基本式 (1)式と(2)式を次の境界条件のもとで解 $<。$

$$
\begin{aligned}
& y=0 \text { で, } E_{1}=E_{2} \quad \text { （電界の連続性） } \ldots(3) \\
& y=0 \text { で } \frac{\partial E_{1}}{\partial y}=\frac{\mu_{a}}{\mu_{e}} \frac{\partial E_{2}}{\partial y}
\end{aligned}
$$

(磁束密度の烡直成分の連秸性)

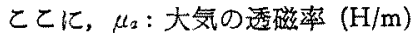

\section{3. 積分変換による求解}

最初比，(2)式の特解 $E_{2}^{(p)}(x, y)$ をフーリエ変换 を用いて求める。

(2)式の両辺䘮 $x, y$ 飞ついてフーリエ变換すると,

$$
-\left(v_{x}{ }^{2}+v_{y}{ }^{2}\right) \hat{E}_{2}=m_{e}{ }^{2} \hat{E}_{2}+C_{0} \frac{m_{e}{ }^{2}}{\sigma_{e}} I
$$

ただし， $\hat{E}_{2}$ は $E_{2}$ のフーリエ変換で、

$$
\begin{aligned}
\hat{E}_{2}= & \int_{-\infty}^{\infty} \int_{-\infty}^{\infty} E_{2}(x, y) e^{-j v_{x} x} \cdot e^{-j v_{y}(y+h)} \\
& \times d x d(y+h) \ldots \ldots \ldots \ldots \ldots \ldots \ldots \ldots
\end{aligned}
$$

(5)式加ら

$$
\hat{E}_{2}=-C_{0} \frac{m_{e}^{2}}{\sigma_{e}} \frac{I}{v_{x}^{2}+v_{y}^{2}+m_{e}^{2}}
$$

であるから，(6)式より，

$$
\begin{aligned}
& E_{2}{ }^{(p)}(x, y)=-\frac{C_{0}}{4 \pi^{2}} \frac{m_{e}{ }^{2} I}{\sigma_{e}} \\
& \quad \times \int_{-\infty}^{\infty} \int_{-\infty}^{\infty} \frac{e^{j v_{x} x+j v_{y}(y+h)}}{v_{x}^{2}+v_{y}^{2}+m_{e}^{2}} d v_{x} d v_{y}
\end{aligned}
$$

ここで, $v_{x}=u \cos \theta, v_{y}=u \sin \theta$ とおくと,

$$
\begin{aligned}
& v_{x^{2}}+v_{y}{ }^{2}=u^{2} \\
& \frac{\partial\left(v_{x}, v_{y}\right)}{\partial(u, \theta)}=\left|\begin{array}{cc}
\cos \theta & -u \sin \theta \\
\sin \theta & u \cos \theta
\end{array}\right|=u
\end{aligned}
$$

徉って，(7)式は

$$
\begin{aligned}
E_{2}(p)(x, y)= & -\frac{C_{0}}{4 \pi^{2}} \frac{m_{e}^{2} I}{\sigma_{e}} \int_{0}^{\infty} u d u \\
& \times \int_{0}^{2 \pi} \frac{e^{j u r \sin (\theta+\varphi)}}{u^{2}+m_{e}{ }^{2}} d \theta
\end{aligned}
$$

と表せる。ただし，

$$
r=\sqrt{x^{2}+(y+h)^{2}}, \quad \varphi=\tan ^{-1} \frac{x}{y+h}
$$

である。

雾次の第一種ベッセル関数 $J_{0}(Z)$ に関する公式 (7),

$$
\begin{aligned}
J_{0}(Z) & =\frac{1}{2 \pi} \int_{\alpha}^{2 \pi+\alpha} e^{-j Z \sin \theta} d \theta \\
& =\frac{1}{2 \pi} \int_{\alpha}^{2 \pi+\alpha} e^{j Z \sin \theta} d \theta
\end{aligned}
$$

を用いると（8)式は

$$
E_{2}^{(p)}(x, y)=-\frac{C_{0} m_{e}^{2} I}{2 \pi \sigma_{e}} \int_{0}^{\infty} \frac{u J_{0}(r u)}{u^{2}+m_{e}^{2}} d u
$$

之なる。 $(9)$ 式に零次の第二種変形ベッセル関数 $K_{0}$ (ay) 江関する次の公式 ${ }^{(7)}$,

$$
K_{0}(a y)=\int_{0}^{\infty} \frac{x J_{0}(a x)}{x^{2}+y^{2}} d x \quad(\operatorname{Re} y>0)
$$

をあてはめ, $a=r, y=m_{\epsilon}$ とおくと，

$$
E_{2}{ }^{(p)}(x, y)=-\frac{C_{0} m_{e}{ }^{2} I}{2 \pi \sigma_{e}} K_{0}\left(m_{e} r\right)
$$

を得る。

(10)式が (2)式の特解である。その物理的意味は, 大地中十分深い位置化電流 $I$ の流れる絶縁された導体 が埋設されたときに生ずる大地中の電界を表してい る。あるいは，变位電流が無視できる領域で周波数が 十分高いときに，大地中に埋設されている絶縁された 導体の中心に電流 Iが流れている場合の該導体近仿の 大地中電界之あ解积できる。

次に，(1)式捄よび(2)式の右辺第 2 項を 0 とした 式の余関数を求める。これらの式をそれぞれ $x$ につ いてフーリエ変換すると,

$$
\begin{aligned}
& \frac{\partial^{2} \hat{E}_{1}}{\partial y^{2}}-\alpha^{2} \hat{E}_{1}=0 \ldots \ldots . . . \\
& \frac{\partial^{2} \hat{E}_{2}}{\partial y^{2}}-\left(\alpha^{2}+m_{e}^{2}\right) \hat{E}_{2}=0
\end{aligned}
$$

ただし，

$$
\begin{aligned}
& \hat{E}_{1}=\hat{E}_{1}(y)=\int_{-\infty}^{\infty} E_{1}(x, y) e^{-j \alpha x} d x \\
& \hat{E}_{2}=\hat{E}_{2}(y)=\int_{-\infty}^{\infty} E_{2}(x, y) e^{-j \alpha x} d x
\end{aligned}
$$

(11)，(12)式の解，すな斿古余関数 $\hat{E}_{1}^{(q)}, \hat{E}_{2}^{(q)}$ は 次のように表せる。 


$$
\begin{aligned}
& \hat{E}_{1}(q)=A_{1} e^{-|\alpha| y}+B_{1} e^{|\alpha| y} \ldots \ldots \ldots \ldots \ldots . . . \\
& \hat{E}_{2}(q)=A_{2} e^{-\sqrt{\alpha^{q}+m_{i}^{2} y}}+B_{2} e^{\sqrt{\alpha^{2}+m_{e}} y}
\end{aligned}
$$

ところで，無限遠においては電界は 0 となるべきで あるから, $y \rightarrow+\infty$ で $\hat{E}_{1}^{[q]}=0, y \rightarrow-\infty て ゙ \hat{E}_{2}^{(p)}+$ $\hat{E}_{2}^{(p)}=0$ である。これらの条件から。

$$
B_{1}=A_{2}=0
$$

従って,

$$
\begin{aligned}
& \hat{E}_{1}(q)=A_{1} e^{-|\alpha| y} \ldots \ldots \\
& \hat{E}_{2}(q)=B_{2} e^{\sqrt{\alpha^{2}+m e^{3} y}}
\end{aligned}
$$

次任，境界条件の (3)，(4)式を用いて $A_{1}$ と $B_{2}$ を 決定する。

まず，さきに求めた特解 (10)式から，

$$
\begin{aligned}
& E_{2}{ }^{(p)}(x, y) \\
& \quad=D_{0} I \int_{-\infty}^{\infty} \frac{\left.e !-|y+h| \sqrt{\alpha^{2}+m e^{2}}+j \alpha x\right\}}{2 \sqrt{\alpha^{2}+m_{e}^{2}}} d \alpha
\end{aligned}
$$

ここK,

$$
D_{0}=-\frac{C_{0} m_{e}^{2}}{2 \pi \sigma e}
$$

(18)式を $x$ 亿ついてフーリエ変換すると,

$$
\begin{aligned}
\hat{E}_{2}{ }^{(p)}(y) & \\
= & D_{0} I \int_{-\infty}^{\infty}\left[\int_{-\infty}^{\infty} \frac{e\left\{-|\nu+h| \sqrt{\alpha^{2}+m_{e}^{2}}+j \alpha x\right\}}{2 \sqrt{\alpha^{2}+m_{e}^{2}}}\right. \\
& \times d \alpha] e^{-j \alpha x} d x \\
= & \pi D_{0} I \frac{e-|\nu+h| \sqrt{\alpha^{2}+m_{e}^{2}}}{\sqrt{\alpha^{2}+m_{e}^{2}}} \ldots \ldots \ldots \ldots \ldots(19)
\end{aligned}
$$

上式を $y$ で偏微分すれば。

$$
\frac{\partial \hat{E}_{2}{ }^{(p)}(y)}{\partial y}=-\pi D_{0} I e-|y+h| \sqrt{\alpha^{2}+m_{0}^{2}} \ldots
$$

境界条件の式（3)，(4)加万，

$$
\begin{aligned}
& \hat{E}_{1}\left(0_{+}\right)=\hat{E}_{2}\left(0_{-}\right) \\
& \frac{\partial \hat{E}_{1}\left(0_{+}\right)}{\partial y}=\frac{\mu_{a}}{\mu_{e}} \frac{\partial \hat{E}_{2}\left(0_{-}\right)}{\partial y}
\end{aligned}
$$

また,

$$
\begin{aligned}
& \hat{E}_{1}\left(0_{+}\right)=\hat{E}_{1}^{(q)}\left(0_{+}\right) \\
& \hat{E}_{2}\left(0_{-}\right)=\hat{E}_{2}^{(p)}\left(0_{-}\right)+\hat{E}_{2}^{(q)}\left(0_{-}\right)
\end{aligned}
$$

であるから，(16)，(17)，(19)式捄よび(20)式の関係を 用いて，上記の条件をあてはめると，

$$
\begin{gathered}
A_{1}=\pi D_{0} I \frac{e^{-h \sqrt{\alpha^{2}+m_{e}^{2}}}}{\sqrt{\alpha^{2}+m_{e}^{2}}}+B_{2} \\
-|\alpha| A_{1}=-\pi D_{0} I \frac{\mu_{a}}{\mu_{e}} e^{-h \sqrt{\alpha^{2}+m_{e}^{2}}} \\
+\frac{\mu_{a}}{\mu_{e}} \sqrt{\alpha^{2}+m_{e}^{2}} B_{2}
\end{gathered}
$$

電学墖 B, 107 巻 6 号, 昭 62
上の 2 個の式から， $A_{1}$ 上 $B_{2}$ 吕次のように決定さ れる。

$$
\begin{aligned}
& A_{1}=\frac{2 \pi D_{0} I}{|\alpha|+\frac{\mu_{a}}{\mu_{e}} \sqrt{\alpha^{2}+m_{e}^{2}}} \frac{\mu_{a}}{\mu_{e}} e^{-\hbar \sqrt{\alpha^{2}+m_{e}^{2}}} \\
& B_{2}=\frac{\pi D_{0} I}{|\alpha|+\frac{\mu_{a}}{\mu_{e}} \sqrt{\alpha^{2}+m_{e}^{2}}}\left(\frac{\mu_{a}}{\mu_{e}}-\frac{|\alpha|}{\sqrt{\alpha^{2}+m_{e}^{2}}}\right)
\end{aligned}
$$

従って，(16)，(17)，(19)式加ら，

$$
\begin{aligned}
\hat{E}_{1}(y)= & \frac{2 \pi D_{0} I}{\frac{\mu_{e}}{\mu_{a}}|\alpha|+\sqrt{\alpha^{2}+m_{e}^{2}}} e-h \sqrt{\alpha^{2}+m_{e}{ }^{2}}-|\alpha| y \\
\hat{E}_{2}(y)= & \pi D_{0} I \\
& \times\left\{\frac{e-|y+h| \sqrt{\alpha^{2}+m_{e}^{2}}}{\sqrt{\alpha^{2}+m_{e}^{2}}}-\frac{e-(h-y) \sqrt{\alpha^{2}+m_{e}^{2}}}{\sqrt{\alpha^{2}+m_{e}^{2}}}\right. \\
& \left.+\frac{2 e-(h-y) \sqrt{\alpha^{2}+m_{e} e^{2}}}{\frac{\mu_{e}}{\mu_{e}}|\alpha|+\sqrt{\alpha^{2}+m_{e}^{2}}}\right\} \ldots \ldots \ldots \ldots \ldots \ldots \ldots \ldots \ldots(24)
\end{aligned}
$$

(23)，(24)式を逆フーリエ変換すると，解 $E_{1}(x, y)$ 之 $E_{2}(x, y)$ が次のように表せる。

$$
\begin{aligned}
& E_{1}(x, y)= D_{0} I \int_{-\infty}^{\infty} \frac{e-|\alpha| y-h \sqrt{\alpha_{e}{ }^{2}+m_{e}{ }^{2}}}{\mu_{a}}|\alpha|+\sqrt{\alpha^{2}+m_{e}^{2}} \\
& \times e^{j \alpha x} d \alpha \ldots \ldots \ldots \ldots \ldots \ldots . .(25) \\
& E_{2}(x, y)= D_{0} I \\
& \times \int_{-\infty}^{\infty}\left\{\frac{e-|y+h| \sqrt{\alpha^{2}+m_{e}^{2}}}{2 \sqrt{\alpha^{2}+m_{e}^{2}}}-\frac{e-(h-y) \sqrt{\alpha^{2}+m_{e}^{2}}}{2 \sqrt{\alpha^{2}+m_{e}^{2}}}\right. \\
&\left.+\frac{e-(h-y) \sqrt{\alpha^{2}+m_{e}^{2}}}{\frac{\mu_{e}}{\mu_{a}}|\alpha|+\sqrt{\alpha^{2}+m_{e}^{2}}}\right\} e^{j \alpha x} d \alpha \ldots \ldots(26)
\end{aligned}
$$

\section{4. 大地帰路相互インピーダンスの計算式}

図1に示した二つの導体 $A, B$ 間の大地帰路相互1 ンピーダンスを $Z_{m}$ とすると，

$$
Z_{m}=-\frac{E_{2}(X, Y)}{I}
$$

である。

前章で求めた解 (26)式を用い, $\mu_{a}=\mu_{c}=\mu_{0}$ と仮定す れば， $Z_{m}$ は次式のように表される。

$$
\begin{aligned}
Z_{m}= & \frac{j \omega \mu_{0}}{2 \pi r_{i} m_{e} K_{1}\left(m_{e} r_{i}\right)}\left\{K_{0}\left(m_{e} R\right)\right. \\
& -K_{0}\left(m_{e} R^{\prime}\right)+\int_{-\infty}^{\infty} \frac{e-|h-Y| \sqrt{\alpha^{2}+m_{e}}}{|\alpha|+\sqrt{\alpha^{2}+m_{e}^{2}}} \\
& \left.\times e^{j \alpha X} d \alpha\right\} \ldots \ldots \ldots \ldots \ldots \ldots \ldots \ldots(28)
\end{aligned}
$$


ここに

$$
R=\sqrt{X^{2}+(h+Y)^{2}}, \quad R^{\prime}=\sqrt{X^{2}+(h-Y)^{2}}
$$

$K o(\cdot)$ は零次の第二種変形ベッセル関数で，

$$
\begin{aligned}
& K_{0}\left(m_{e} R\right)=\int_{-\infty}^{\infty} \frac{e-|h+Y| \sqrt{\alpha^{2}+m_{e} e^{2}}}{2 \sqrt{\alpha^{2}+m_{e}^{2}}} e^{j \alpha X} d \alpha \\
& K_{0}\left(m_{e} R^{\prime}\right)=\int_{-\infty}^{\infty} \frac{e-|h-Y| \sqrt{\alpha^{2}+m_{e}{ }^{3}}}{2 \sqrt{\alpha^{2}+m_{e}^{2}}} e^{j \alpha X} d \alpha
\end{aligned}
$$

(28)式の $\{\cdot\}$ の第 3 項の積分を害行すると，

$$
\begin{aligned}
& \int_{-\infty}^{\infty} \frac{e^{-|h-Y| \sqrt{\alpha^{2}+m_{e}^{2}}}}{|\alpha|+\sqrt{\alpha^{2}+m_{e}^{2}}} e^{j \alpha X} d \alpha \\
& =\frac{2 L^{2}}{R^{\prime 2}} K_{0}\left(m_{e} R^{\prime}\right)+\frac{2\left(L^{2}-X^{2}\right)}{R^{\prime 3} m_{e}} K_{1}\left(m_{e} R^{\prime}\right) \\
& -\frac{2\left(L^{2}-X^{2}\right)}{R^{14} m_{e}^{2}}\left(1+m_{e} L\right) e^{-m_{e} L} \\
& +\frac{2 L|X|}{R^{\prime 2}} S\left(m_{e} R^{\prime},|X|, L\right)
\end{aligned}
$$

ここに,

$$
L=h-Y
$$

$K_{1}(\cdot)$ は, 一次の第二董変形ベッセル関数である。

$S\left(m_{e} R^{\prime},|X|, L\right)$ は, 次の (30) 式で示すような関数 である。

$$
\begin{aligned}
S( & \left.m_{e} R^{\prime},|X|, L\right) \\
= & \frac{L|X|}{R^{\prime 2}}-m_{e} R^{\prime}\left\{\frac{2}{3} \frac{|X|}{R^{\prime}}\left(\frac{L}{R^{\prime}}\right)^{2}+\frac{1}{3} \frac{|X|}{R^{\prime}}\right\} \\
& +\sum_{k=1}^{\infty} \frac{\left(m_{e} R^{\prime}\right)^{2 k}}{(2 k+2)(2 k) ! !(2 k-1) ! !} \\
& \times\left[2 \frac{|X|}{R^{\prime}}\left(\frac{L}{R^{\prime}}\right)^{2 k+1}+\frac{(2 k-1) ! !}{(2 k-2) ! !}\right. \\
& \times\left\{\sum_{\nu=1}^{k} \frac{(2 \nu-2) ! !}{(2 \nu-1) ! !} \frac{|X|}{R^{\prime}}\left(\frac{L}{R^{\prime}}\right)^{2 \nu-1}\right. \\
& \left.\left.+\tan ^{-1} \frac{|X|}{L}\right\}\right] \\
& -\sum_{k=1}^{\infty} \frac{\left(m_{e} R^{\prime}\right)^{2 k+1}}{(2 k+3)(2 k+1) ! !(2 k) ! !} \\
& \times\left[2 \frac{|X|}{R^{\prime}}\left(\frac{L}{R^{\prime}}\right)^{2 k+2}+\frac{(2 k) ! !}{(2 k-1) ! !}\right. \\
& \left.\times\left\{\sum_{\nu=1}^{k} \frac{(2 \nu-1) ! !}{(2 \nu) ! !} \frac{|X|}{R^{\prime}}\left(\frac{L}{R^{\prime}}\right)^{2 \nu}+\frac{|X|}{R^{\prime}}\right\}\right]
\end{aligned}
$$

ここk

$$
\begin{aligned}
& (2 k) ! !=2 k \cdot(2 k-2) \cdots \cdots \cdot 4 \cdot 2 \\
& (2 k-1) ! !=(2 k-1) \cdot(2 k-3) \cdots \cdots 3 \cdot 1
\end{aligned}
$$

(29)式の関係を(28)式に代入すると， $Z_{m}$ は次の上 うに表される。

$$
\begin{aligned}
Z_{m}= & j \frac{\omega \mu_{0}}{2 \pi r_{i} m_{e} K_{1}\left(m_{e} r_{i}\right)}\left(K_{0}\left(m_{e} R\right)\right. \\
& +\frac{L^{2}-X^{2}}{R^{\prime 2}}\left\{K_{0}\left(m_{e} R^{\prime}\right)+\frac{2}{m_{e} R^{\prime}} K_{1}\left(m_{e} R^{\prime}\right)\right.
\end{aligned}
$$

$$
\begin{aligned}
& \left.-\frac{2}{m_{e}^{2} R^{\prime 2}}\left(1+m_{e} L\right) e^{-m_{e} L}\right\} \\
& \left.+\frac{2 L|X|}{R^{\prime 2}} S\left(m_{e} R^{\prime},|X|, L\right)\right] .
\end{aligned}
$$

(31)式において, $\left|m_{e} r_{i}\right| \ll 1,\left|m_{\epsilon} R\right| \ll 1$ および $\left|m_{e} R^{\prime}\right| \ll 1$ の場合は，次の近似が適用できる。

$$
\begin{aligned}
& m_{e} r_{i} K_{1}\left(m_{e} r_{i}\right) \simeq 1 \\
& K_{0}\left(m_{e} R\right) \simeq-\ln \frac{\gamma m_{e} R}{2} \\
& K_{0}\left(m_{e} R^{\prime}\right) \simeq-\ln \frac{\gamma m_{e} R^{\prime}}{2} \\
& \frac{K_{1}\left(m_{e} R^{\prime}\right)}{m_{e} R^{\prime}} \simeq \frac{1}{2} \ln \frac{\gamma m_{e} R^{\prime}}{2}+\frac{1}{m_{e}^{2} R^{\prime 2}}-\frac{1}{4} \\
& \frac{\left(1+m_{e} L\right) e^{-m_{e} L}}{m_{e}{ }^{2} R^{\prime 2}} \simeq \frac{1}{m_{e}^{2} R^{\prime 2}}-\frac{L^{2}}{2 R^{\prime 2}}+\frac{m_{e} L^{3}}{3 R^{\prime 2}} \\
& S\left(m_{e} R^{\prime},|X|, L\right) \simeq \frac{|X| L}{R^{\prime 2}} \\
& \quad-m_{e}\left(\frac{2|X| L^{2}}{3 R^{\prime 2}}+\frac{|\dot{X}|}{3}\right)
\end{aligned}
$$$$
\text { ここに, } \gamma=1.7811 \text { (オイラー定数) }
$$

これらの近似が許される条件のもとでは，(31)式の $Z_{m}$ は次のような簡単な形の式となる。

$$
Z_{m} \simeq j \frac{\omega \mu_{0}}{2 \pi}\left(\frac{1}{2}-\ln \frac{\gamma m_{e} R}{2}-\frac{2}{3} m_{e} L\right) \ldots
$$

(32)式は，Pollaczek 氏が発表した近似式(4) と完全 に一致している。

\section{5. 計 算 例}

前章で導出した(31)式の形から， $A, B 2$ 導体の埋 設位置之絶緑半径が与えられれぱ， $Z_{m} / \omega$ の值は実部

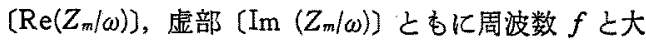
地導電率 $\sigma$ ：との積 $f \sigma$ ：にのみ依存すると言える。 そこで,

$$
\begin{aligned}
& \frac{Z_{m}}{\omega}=\operatorname{Re}\left(Z_{m} / \omega\right)+j \operatorname{Im}\left(Z_{m} / \omega\right) \\
& =G+j H \text {. }
\end{aligned}
$$

之置き， $G$ または $H$ と $f \sigma_{e}$ との関係を求めておけ ば，一般的で実用的な資料として利用できる。

図2は，導体 $A$ 招上び $A$ 之の間で相互インピーダ ンスの計算対象となる導体 $B 1, B 2, \cdots, B 15$ の䭪設 位置を示す。 $A$ と $B I(I=1,2, \cdots, 15)$ 之の間の大地帰 路相互インピーダンスを $Z_{A B I}$ とし， $Z_{A B I}$ の計算に必 要な $X, Y$ と $R, R^{\prime}$ および $L$ の値を表 1 に示した。 すべてのケースに対し， $r_{i}=0.05 \mathrm{~m}$ とした。

図3は， $A$ と $B I(I=1,2,3)$ 之が水平の位置関係儿 ある場合，図 4 ，図 5 はそれぞれ $A$ に対し $B I(I$ 
$=4,5,6$ および $7,8,9)$ が鉛直上方および鉊直下方に ある場合の $Z_{A B I} / \omega$ 対 $f \sigma e$ の計算結果を示す。また， 圀6，図 7 は，それぞれ $A$ に対し $B I(I=10,11,12$ および 13，14，15）が斜め上方および斜め下方にある 場合の同様の計算結果を示す。

因3から困7において，横軸の $f \sigma$ 。の值は $10^{5}$ ま でとしたが, 例えば $\sigma_{\epsilon}=0.01 \mathrm{~S} / \mathrm{m}$ のときは, $f=10^{7}$

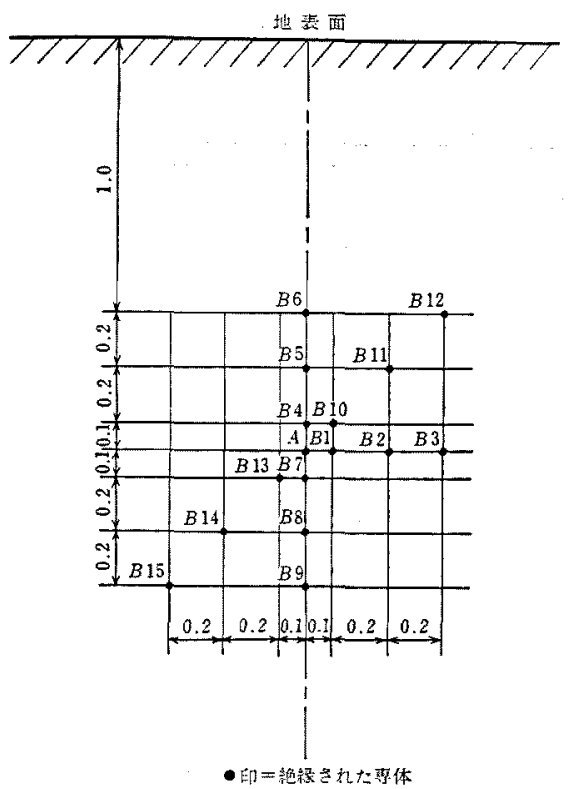

园 $2 Z_{A B I}(I=1,2, \cdots, 15)$ 計算用の導体配列

Fig. 2. Configuration for calculation of $Z_{A B I}$ $(I=1,2, \cdots, 15)$.
$\mathrm{Hz}=10 \mathrm{MHz}$ までの大地帰路相互インピーダンスの 値がこれらの図加ら求められる。

図 3〜図 7 までの計算結果から，A 亿対する $B I$ の 位置が，水平，鉛直，斜めのいずれの方向にあっても 大地帰路相互インピーダンスの值は， $A$ と $B I$ 間の距 離 $R$ が同じであれば，実用上は活ぼ同值之言える。

圆 8 は, $A$ 上 $B I$ 亡が水平の位置関係にある $I=1$, 2, 3 のケースについて, fo。 の值をパラメータとし， $Z_{A B I} / \omega$ をベクトル $G_{A B I}+j H_{A B I}$ の先端の軌跡として 示した図である。これは图 3 の結果を別の形で表現し たあのにすぎないが，fo。が变化したとき $G_{A B I}$ より も $H_{A B I}$ のほうが，はるかに敏感に变化するととを明 りょうに示している。

本資料では，大地中での電界に関する偏微行方程式 を(2)式の形とし $Z_{m}$ を求めたが，その際，付録に示 したように， $C_{0}=\left\{m_{e} r_{i} K_{1}\left(m_{e} r_{i}\right)\right\}^{-1}$ とした。従って, 本資料で求めた $Z_{m}$ 〔(31)式〕は，ヶーブル絶縁外半

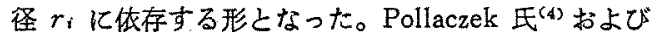
Wedepohl 氏ら ${ }^{(5)}$ の基本式は， $C_{0}=1$ の場合に相当す る。乙れは， $r_{i} \rightarrow 0$ の極限の場合を报ったてとになり， 彼らの求めた $Z_{m}$ の計算式の中には $r_{i}$ が含まれてい ない。そこで，本資料の (31) 式の $Z_{m}$ の $r_{i}$ 依存性を 調べた。

図 9 は，通常のケーブルで考えられる $0<r_{i} \leq 0.075$ $\mathrm{m}$ の範囲で, $G_{A B 2}$ と $H_{A B 2}$ が $f \sigma_{c}=10^{-1}, 10^{2}, 10^{5}$ の各場合でどのように変化するのかを示したものであ る。同図の綐軸の值は， $r_{i} \rightarrow 0\left(C_{0}=1\right)$ の場合の $G_{A B 2}$, $H_{A B 2}$ の值を基準とした相対值で表している。図 9 の

表 1 計算したケース

Table 1. Cases of numerical calculations.

\begin{tabular}{|c|c|c|c|c|c|c|}
\hline \multirow{2}{*}{ 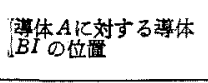 } & \multirow{2}{*}{ 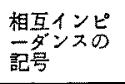 } & \multicolumn{2}{|c|}{ 導体 $B I$ の徙標 } & \multirow{2}{*}{$\begin{array}{c}\text { 導体 } A \text { ¿ } B I \text { 間の距睢 } \\
R=\sqrt{X^{2}+(Y+h)^{2}}\end{array}$} & \multirow[b]{2}{*}{$R^{\prime}=\sqrt{X^{2}+(Y-h)^{2}}$} & \multirow{2}{*}{ 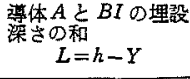 } \\
\hline & & $x$ & $Y$ & & & \\
\hline \multirow{3}{*}{ 水 } & $Z_{A B_{1}}$ & 0.1 & -1.5 & 0.100 & 3,002 & 3.000 \\
\hline & $Z_{A B Z}$ & 0.3 & -1.5 & 0.300 & 3. 015 & 3. 000 \\
\hline & $Z_{A B 3}$ & 0.5 & -1.5 & 0.500 & 3.041 & 3.000 \\
\hline \multirow{3}{*}{ 站直上方 } & $Z_{A B}$ & 0.0 & -1.4 & 0.100 & 2.900 & 2.900 \\
\hline & $Z_{A B 5}$ & 0.0 & -1.2 & 0.300 & 2.700 & 2.700 \\
\hline & $Z_{A B B}$ & 0.0 & $-1,0$ & 0.500 & 2. 500 & 2. 500 \\
\hline \multirow{3}{*}{ 鉛直下方 } & $Z_{A B 7}$ & 0.0 & -1.6 & 0.100 & 3.100 & 3. 100 \\
\hline & $Z_{A B 3}$ & 0.0 & -1.8 & 0.300 & 3.300 & 3. 300 \\
\hline & $Z_{A B B}$ & 0.0 & -2.0 & 0.500 & 3. 500 & 3.500 \\
\hline \multirow{3}{*}{ 斜 め上方 } & $Z_{A B 10}$ & 0.1 & -1.4 & 0.141 & 2.902 & 2. 900 \\
\hline & $Z_{A B 11}$ & 0.3 & -1.2 & 0.424 & 2. 717 & 2.700 \\
\hline & $Z_{A B 12}$ & 0.5 & -1.0 & 0.707 & 2.550 & 2.500 \\
\hline \multirow{3}{*}{ 斜 め下方 } & $Z_{A B ! 3}$ & -0.1 & -1.6 & 0.141 & 3.102 & 3,100 \\
\hline & $Z_{A B 14}$ & -0.3 & $-1,8$ & 0.424 & 3.314 & 3. 300 \\
\hline & $Z_{A B 1 S}$ & -0.5 & -2.0 & 0.707 & 3.536 & 3.500 \\
\hline
\end{tabular}

(数字の単位は $\mathrm{m}, h=1.5 \mathrm{~m}, \tau_{i}=0.05 \mathrm{~m}$ ) 


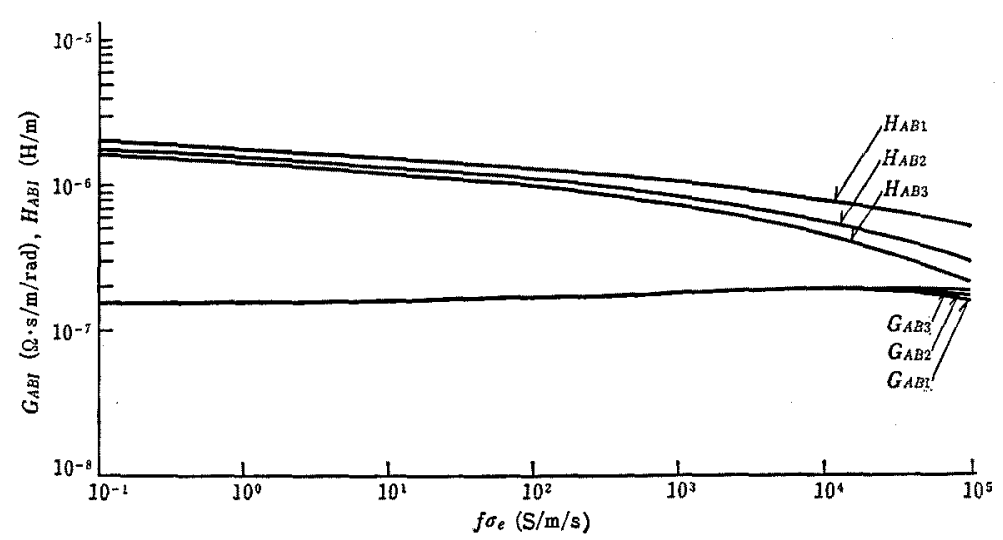

园 $3 Z_{A B I} / \omega\left(=G_{A B I}+j H_{A B I}\right)$ \& fo. の関係 $(I=1,2,3)$

Fig. 3. $Z_{A B I} \mid \omega\left(=G_{A B I}+j H_{A B I}\right)$ vs. $f \sigma .(I=1,2,3)$.

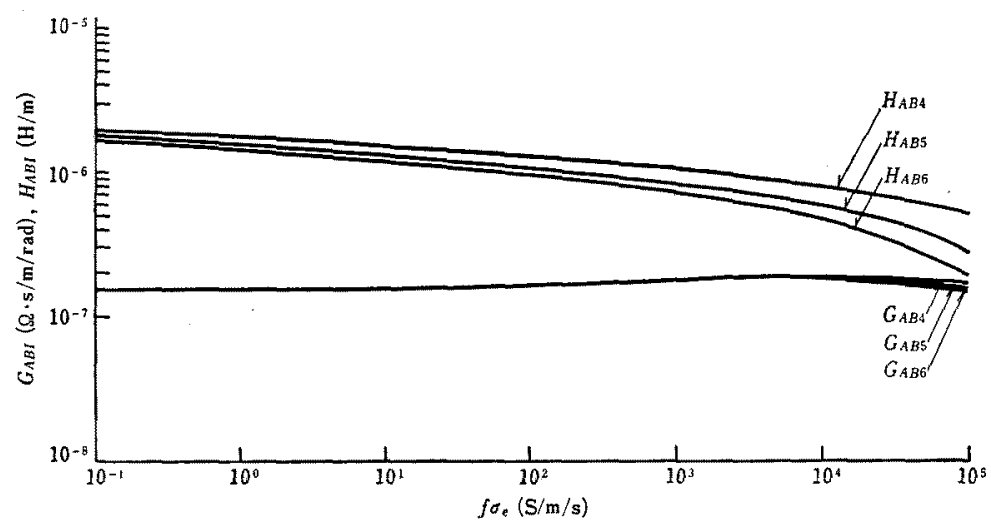

图 $4 Z_{A B I} / \omega\left(=G_{A B I}+j H_{A B t}\right)$ と $f \sigma_{\varepsilon}$ の関係 $(I=4,5,6)$

Fig. 4. $Z_{A B I} / \omega\left(=G_{A B I}+j H_{A B I}\right)$ vs. $f \sigma_{\ell}(I=4,5,6)$.

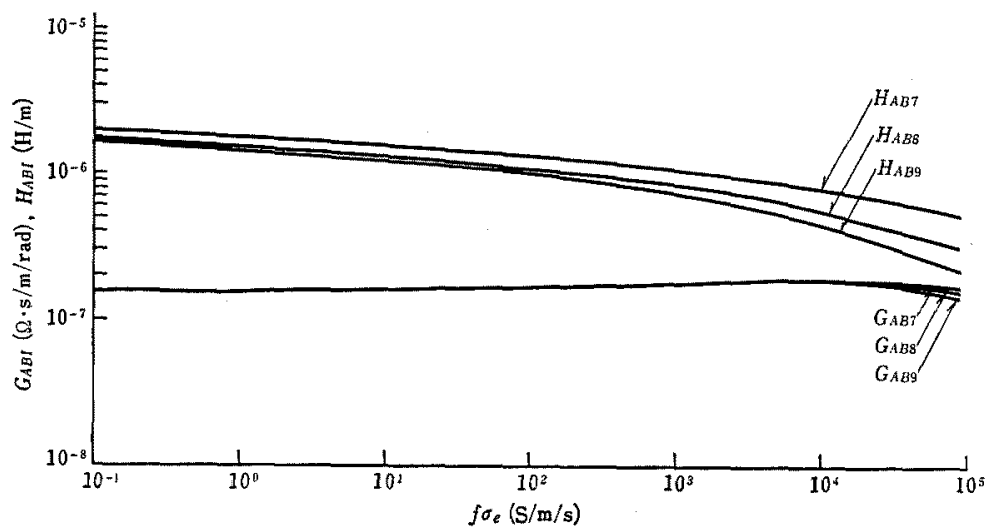

図 $5 Z_{A B I} / \omega\left(=G_{A B I}+j H_{A B I}\right)$ と $f \sigma$ ，の関係 $(I=7,8,9)$

Fig. 5. $Z_{A B I} / \omega\left(=G_{A B I}+j H_{A B I}\right)$ vs. $f \sigma \cdot(I=7,8,9)$.

結果は, $0<r_{i} \leq 0.075 \mathrm{~m}$ の筙囲では, $C_{0}=1$ の場合 とを示している。このととは, (2) 式において, $\left(r_{i} \rightarrow 0\right)$ との差が最も大となる $f \sigma_{e}=10^{5}$ のときです， Pollaczek 氏やWodepohl 氏らのように, $C_{0}=1$ と $Z_{m}$ の実部，虚部とあその差は $\pm 1 \%$ 以内にあるこしてあ実用上何ら問題ないてとを意味している。 


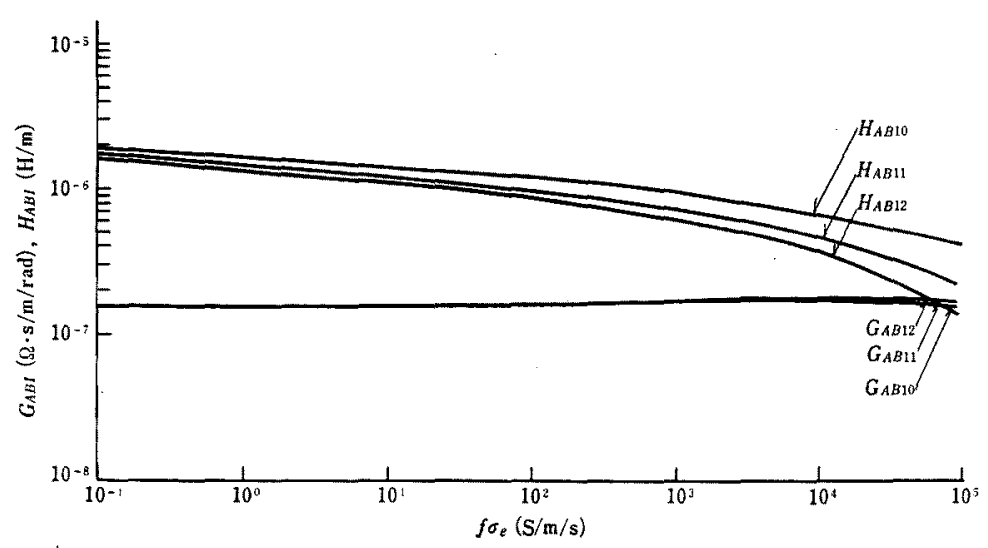

図 $6 Z_{A B I} / \omega\left(=G_{A B I}+j H_{A B I}\right)$ と $f \sigma$. の関係 $(I=10,11,12)$

Fig. 6. $Z_{A B I} / \omega\left(=G_{A B I}+j H_{A B I}\right)$ vs. $f \sigma_{c}(I=10,11,12)$.

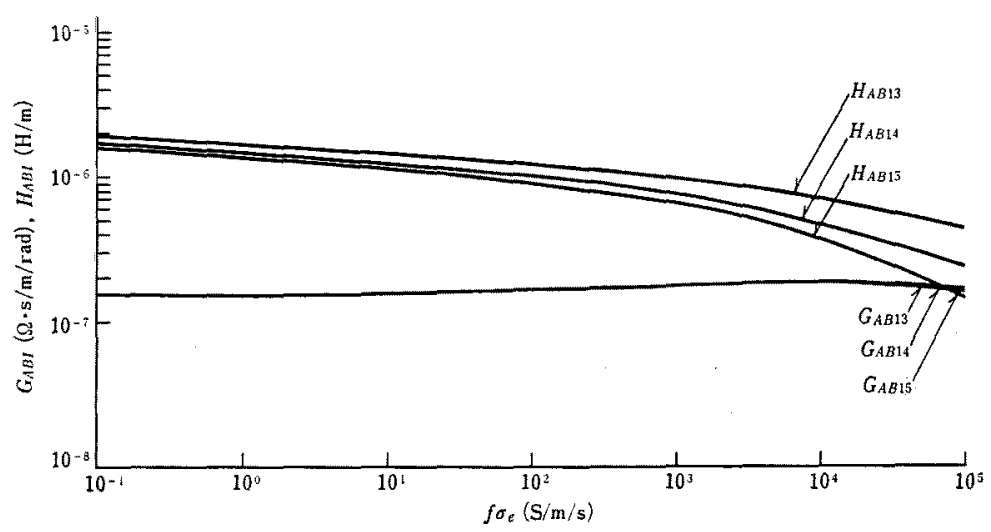

図 $7 Z_{A B I} \mid \omega\left(=G_{A B I}+j H_{A B I}\right)$ とfo. の関係 $(I=13,14,15)$

Fig. 7. $Z_{A B I} / \omega\left(=G_{A B I}+j H_{A B I}\right)$ vs. $f \sigma_{\bullet}(I=13,14,15)$.
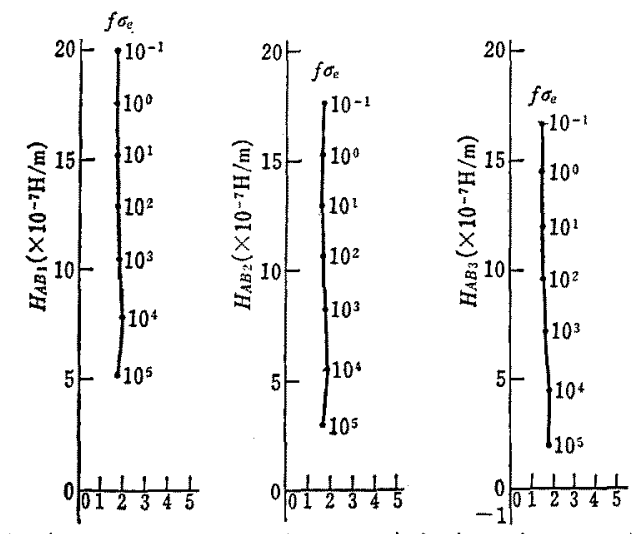

$\boldsymbol{G}_{A B_{1}}\left(\times 10^{-7} \Omega \cdot \mathrm{s} / \mathrm{m} / \mathrm{rad}\right) G_{A B_{2}}\left(\times 10^{-7} \Omega \cdot \mathrm{s} / \mathrm{m} / \mathrm{rad}\right) G_{A B_{3}}\left(\times 10^{-7} \Omega \cdot \mathrm{s} / \mathrm{m} / \mathrm{rad}\right)$ (a) (b)

(c)

(a) $I=1$, (b) $I=2$, (c) $I=3$

图 $8 G_{A B I}+j H_{A B I}$ の先端軌跡

Fig. 8. Loci of $G_{A B I}+j H_{A B I}$.

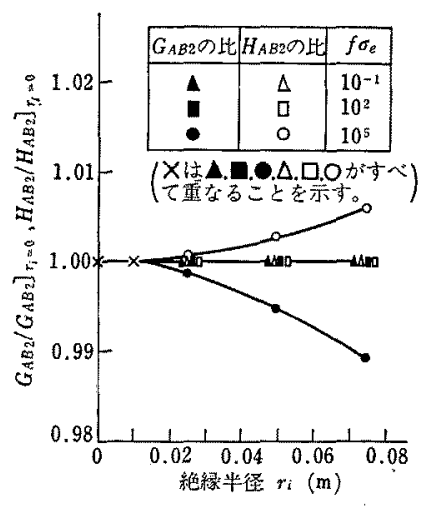

济 $9 Z_{A B 2} / \omega\left(=G_{A B 2}+j H_{A B 2}\right)$ k与光る 絶縁半径 $r i$ 影籍

Fig. 9. Effect of radius of insulation layer $r_{i}$ on $\left.Z_{A B 2}\right] \omega\left(=G_{A B 2}+j H_{A B 2}\right)$. 


\section{6.むすび}

地中に埋設された 2 導体間の大地帰路相互インピー ダンス $Z_{m}$ の周波数依存性を, $Z_{m} / \omega(\omega=2 \pi f)$ を周波 数 $f(\mathrm{~Hz})$ と大地導電率 $\sigma .(\mathrm{S} / \mathrm{m})$ との積 $f \sigma$ 。のみの 関数で表し，一般性のある形式で求好た。

本論文で導出したこのような形式の計算式は，変位 電流が無視できる䇢围 $\left(\sim f \sigma 。<10^{5}\right)$ で使える。種々の

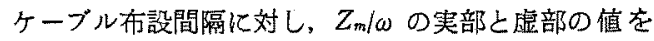
$0.1 \leq f \sigma_{\bullet} \leq 10^{5}$ の範囲で計算し，図表で示した。との ような $Z_{m}$ の計算式之計算結果は，多線条系の地中電 線路の商用周波数からサージ領域にいたる過渡現象の 解析汇寄与できるものと確信する。

（昭和 61 年 10 月 13 日受付）

\section{文献}

(1) J.R. Carson: "Wave Propagation in Overhead Wires with Ground Return", Bell Syst. Tech. J., 5. 539(1926)

(2) F. Pollaczek: "Uber das Feld einer unendlich langen wechselstromdurchfossenen Einfachleitung", Elektr. Na* chr. Tech., 3, 339 (1926)

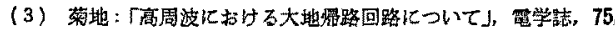
1176 (昭 30-)

(4) F. Pollaczek: "Sur le champ produit par un conducteur simple infiniment long parcouru par un courant alternatifn. Reu. Gén. Elect., XXIX, 851 (1931)

(5) L. M. Wedepohl \& D. J. Wilcox: "Estimation of transient sheath overvoltages in power-cable transmission systems", Proc. Instn Elect. Engrs, 120, 877 (1973)

(6) D.J. Wilcox \& K. J. Lawler: "Transient phenomena in crossbonded cable systems : analytical results", ibid., 125, 999 (1978)

（7）日本数学会释：数学辞典(第三版)（昭 60) 岩波蔡店

\section{付 緑}

\section{本文 (2) 式の中の $C_{0}$ について}

第 3 章で求めた大地中の電界の計算式〔(26)式〕お よび第 4 章に示した(29)式の関係を用いて，図1の導 体 $A$ の絶縁体直上の $y$ 軸上の点 $\left(0,-h+r_{i}\right)$ に利け る電界 $E_{2}\left(0,-h+r_{i}\right)$ を求めると次の上うになる。

$$
\begin{aligned}
E_{2}\left(0,-h+r_{i}\right) & \\
= & D_{0} I\left[K_{0}\left(m_{e} r_{i}\right)+K_{0}\left\{m_{e}\left(2 h-r_{i}\right)\right\}\right. \\
& +\frac{2}{\left(2 h-r_{i}\right)} K_{1}\left\{m_{e}\left(2 h-r_{i}\right)\right\} \\
& \left.-\frac{2\left(1+2 h m_{e}-m_{e} r_{i}\right)}{\left(2 h-r_{i}\right)^{2} m_{e}^{2}} e^{-m_{\theta}\left(2 h-r_{i}\right)}\right]
\end{aligned}
$$

（付 1)式で $h$ が極めて大きい場合，すなわ導体 $A$ 方大地中極めて樑く埋設されている極限を考える 之，右辺（）内の第 2 項以下は 0 に収束する。

乙の場合, $h \rightarrow h$ と記すと,

$$
E_{2}\left(0,-h_{\infty}+r_{i}\right)=D_{0} I K_{0}\left(m_{e} r_{i}\right) \ldots \text { (付 2) }
$$

一方，導体 $A$ 加最初加引大地中極的て深い極限に 埋設さ机ている場合を考えると，導体 $A$ の中心から 距離 $r$ のとてろの地中電界 $E(r)$ 比関して次の関係が 成り立つ。

$$
\frac{1}{r} \frac{\partial}{\partial r}\left(r \frac{\partial E}{\partial r}\right)=m_{e}^{2} E
$$

(付 3 )式の一般解は， $A_{1} ， B_{1}$ を定数として,

$$
E=A_{1} I_{0}\left(m_{e} r\right)+B_{1} K_{0}\left(m_{e} r\right)
$$

之表せる。

$r \rightarrow \infty て ゙ E=0$ であるから， $A_{1}=0$ である。

次江, 電界 $\boldsymbol{E}$ 之磁束密度 $\boldsymbol{B}$ の関係, $\operatorname{rot} \boldsymbol{E}=-\partial \boldsymbol{B} \mid$ $\partial t$ 加

$$
\begin{gathered}
\frac{\partial E}{\partial r}=j \omega B \\
r=r_{i} \text { において, } \\
B=\frac{\mu_{e} I}{2 \pi r_{i}} \ldots
\end{gathered}
$$

である。(付 4 )，(付 5 )式加ら

$$
\begin{aligned}
& B_{1}\left[\frac{\partial K_{0}\left(m_{e} r\right)}{\partial r}\right]_{r=r_{i}}=j \frac{\omega \mu_{e}}{2 \pi r_{i}} I \ldots \ldots \text { (付 } 7 \text { ) } \\
\text { ところで } & \frac{\partial K_{0}\left(m_{e} r\right)}{\partial r}=m_{e} \frac{\partial K_{0}\left(m_{e} r\right)}{\partial\left(m_{e} r\right)}=-m_{e} K_{1}\left(m_{e} r\right)
\end{aligned}
$$

という関係があるから（付 7 )式より

$$
B_{1}=-\frac{j \omega \mu_{e} I}{2 \pi m_{e} r_{i} K_{1}\left(m_{e} r_{i}\right)}
$$

（付 4)，(付 8) 両式加

$$
E\left(r_{i}\right)=-\frac{j \omega \mu_{e} K_{0}\left(m_{e} r_{i}\right)}{2 \pi m_{e} r_{i} K_{1}\left(m_{e} r_{i}\right)} I
$$

(付 9 )式の $E\left(r_{i}\right)$ 之(付 2$)$ 式の $E_{2}\left(0,-h_{\infty}+r_{i}\right)$ 惊 等しいはずであるから，

$$
D_{0}=-\frac{j \omega \mu_{e}}{2 \pi m_{e} r_{i} K_{1}\left(m_{e} r_{i}\right)}
$$

本文(18)式のところで定義したように， $D_{0}$ とC $C_{0}$ の間には, $D_{0}=-\left(C_{0} m_{\iota}{ }^{2}\right) /\left(2 \pi \sigma_{\varepsilon}\right)$ の関係がある。この ことと(付 10)式加ら：C0 快次の上うに決定される。

$$
C_{0}=\frac{1}{m_{e} r_{i} K_{1}\left(m_{e} r_{i}\right)}
$$

